
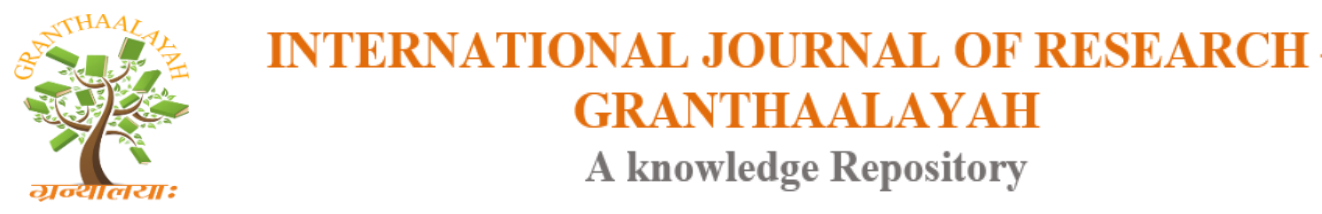

Social

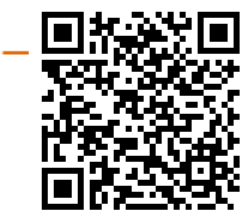

\title{
THE EFFECT OF EXPLICIT INSTRUCTION BY USING PHRASE STRUCTURE RULES ON ACQUISITION OF NOUN CLAUSES
}

\author{
Palida Chaiyapho ${ }^{1}$, Wachiraporn Kijpoonphol ${ }^{2}$ \\ ${ }^{1,2}$ Faculty of Liberal Arts, Ubon Ratchathani University, Thailand
}

\begin{abstract}
The aim of the study was to examine the effect of explicit instruction by using phrase structure rules on acquisition of noun clauses functioning as a subject, an object of a verb and an object of the preposition since they are considered a complex structure that poses difficulty for students learning English. The participants were one class of 12th grade students studying at a secondary school in Surin, Thailand. The instruments used to collect the data were a pretest and posttest and a semi-structured interview. There were 16 training sessions. Each session was conducted within the 50-minute class period. The results of the tests showed that the explicit instruction using phrase structure rules helped improve the participants' knowledge of noun clauses and helped the participants acquire noun clauses. The results of the semi-structured interview revealed that the participants' opinions toward the explicit instruction using phrase structures rules were mostly positive. Many of them said that phrase structure rules helped them understand the structures and functions of noun clauses, which also helped improve their reading skills.
\end{abstract}

Keywords: Explicit Instruction; Phrases Structure Rules; Noun Clauses.

Cite This Article: Palida Chaiyapho, and Wachiraporn Kijpoonphol. (2018). "THE EFFECT OF EXPLICIT INSTRUCTION BY USING PHRASE STRUCTURE RULES ON ACQUISITION OF NOUN CLAUSES.” International Journal of Research - Granthaalayah, 6(6), 377-388. https://doi.org/10.29121/granthaalayah.v6.i6.2018.1382.

\section{Introduction}

Many teachers have tried to apply several methods, techniques and activities to encourage students to improve their language proficiency. Grammar teaching technique is also one of the techniques that the teachers provide for the students. However, there were some problems in teaching English to Thai students. Grammar was one of them. Teaching grammar was considered to be the most difficult part for Thai students especially in acquiring English complex grammar structures. Anderson (2005) suggested that one important factor for successful acquisition of grammatical complex structures is explicit teaching methods. 


\section{Explicit Instruction}

Archer and Hughes (2011) pointed out that an explicit instruction is a structured, systematic and effective methodology that is unambiguous and direct for teaching academic skills. By mean of unambiguous and direct, the instructional design and delivery procedures should consist of clear statements about the purpose and rationale for learning, clear explanations and demonstrations of the instructional target, and supported practice with feedback until independent master has been achieved. Ling's findings supported to the claim that explicit grammar teaching is the teaching methods making the form as the center and emphasizes to learn the grammatical rules purposefully. It correspondingly directs attention to the target forms (Ling, 2015).

Andrews (2007) remarked that the instructor may give examples first and then guide the students to elicit the rules. In his study, students frequently practiced the form in communicative output tasks such as mini grammar quiz and writing prompt. Hall and Vue (2004) explained that to design well-organized explicit instruction, two components need to be included. The first component is "visible delivery features" that consists of group instruction with a high level of teacher and student interactions. The second component is "the less observable instructional design principles and assumptions" that make up the content and strategies to be taught.

In addition, explicit instruction provides gradual explanations to stimulate learners participate in the lesson, modeling to activate learners' knowledge both new and existing knowledge and enhancing in guided practice that learners have to individually practice the skill. Then, they can connect the new to the previous knowledge. In other words, these cause systematically improving background knowledge and explicitly administering it and connecting it to new knowledge.

From the definitions and descriptions, explicit instruction is an interactive well-organized instructional approach for teaching grammar rules. It also has to be unambiguous precise.

\section{Phrase Structure Rules}

Phrase structure rules also known as rewrite rules are rules that generate sentences from words and phrases. Additionally, Jacobs (1995 as cited in Kim, 2013) mentioned that the phrase structure rules make explicit three important basic properties of sentence grammar which are linearity, hierarchy and category. As stated in Brinton and Brinton (2010), a phrase structure rule consists of a set of ordered rules, which are applied stepwise.

A sentence can be written as a noun phrase pluses a verb phrase which can be rewritten in a phrase structure rule as S NP VP>'a sentence consists of a noun phrase followed by a verb phrase". It can be illustrated by a phrase structure tree (a tree diagram with syntactic category information) as shown below.

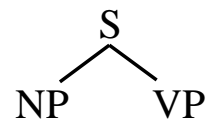


1) Phrase Structure Rules for Noun Phrase (NP)

The noun phrase is a group of words that identifies a person, animal, place, thing, or idea. It can act as both subject and object of the sentence. The noun phrase can be expanded in many different ways as following:
1) $\mathrm{NP} \rightarrow \mathrm{N}$
Cats
2) $\mathrm{NP} \rightarrow \operatorname{Det} \mathrm{N}$ the cats
3) $\mathrm{NP} \rightarrow$ Det Adj N
the small cats
4) $\mathrm{NP} \rightarrow \operatorname{Det} \mathrm{Adj}^{+} \mathrm{N}$
the small white cats
5) $\mathrm{NP} \rightarrow \operatorname{Det}_{\mathrm{Adj}}^{+} \mathrm{N}$ PP the small white cats from the garden
6) $\mathrm{NP} \rightarrow \mathrm{NP} \mathrm{S}$ the cat (that) I kicked
7) $\mathrm{NP} \rightarrow \mathrm{NP}$ Poss NP
Cats' legs
8) $\mathrm{NP} \rightarrow \mathrm{NP}^{+}$Conj NP Cats and dogs
9) $\mathrm{NP} \rightarrow$ Pro They
10) $\mathrm{NP} \rightarrow \mathrm{PN}$ Tom

2) Phrase Structure Rules for Prepositional Phrase (PP)

The prepositional phrases are groups of words containing prepositions that indicate the relationships between various elements within a sentence. The prepositional phrase can similarly be expanded in many different ways as following:
1) $\mathrm{PP} \rightarrow \mathrm{P} \mathrm{NP}$
(the white cats) from the garden
2) $\mathrm{PP} \rightarrow \mathrm{P} \mathrm{PP}$
(the white cats ran out) from inside the house.
3) $\mathrm{PP} \rightarrow \mathrm{P} \mathrm{S}$
4) $\mathrm{PP} \rightarrow \mathrm{PP}^{+}$Conj $\mathrm{PP}$ (Tom is disappointed) by what you did (the white cats) from the garden and from the temple

3) Phrase structure rules for Sentence or Clause (S)

The sentence or clause that can be used by themselves is called an independent clause. Conversely, the clause that does not express a complete thought and cannot stand by itself as a sentence is called a dependent (or subordinate) clause. The following shows some examples of phrase structure rules for independent and dependent clauses.

Independent Clause

1) $\mathrm{S} \rightarrow \mathrm{NP}$ VP

The white cats ran out from inside the house.

2) $\mathrm{S} \rightarrow \mathrm{S}$ VP What you did to me is very bad.

Dependent Clause

3) $\mathrm{S} \rightarrow$ That $\mathrm{S}$

4) $\mathrm{S} \rightarrow$ Wh-word $\mathrm{S}$

That Tom failed the exam (is not surprising)

i. (It's not true) (that) Tom failed the exam What you did last night (disappointed me)

i. (I am disappointed by) what you did last night

ii. (The book) which I bought yesterday (is good)

5) $\mathrm{S} \rightarrow$ AdvSub $\mathrm{S}$

Although it is very late at night, (buses are still crowded) (AdvSub = Adverbial subordinators: although, if, while, after, since, and because, etc.) 


\section{Previous Studies}

There were several studies related to the use of explicit teaching to teach grammar. However, only some studies were mentioned. Rahimpour and Salimi (2010) found that explicit formal instruction of the language improved second language learners' accuracy and acquisition. The explicit formal instruction which was focus on form was used as a treatment. The participants consisted of 30 preuniversity learners selected randomly out of 100 learners at Ghalamchi Institute in Miyandoad in Iran. They were all female with similar proficiency level and were divided into two groups; a treatment group and a control group. Pre-university English text book was used as the instructional material, and the multiple-choice test on the forms focused was used as the testing material. In the procedure session, the experimental group received feedback in the form of recast whereas the control group didn't receive any treatment. The experimental group proceeded 10 hours of explicit instruction on adjective clauses in communicative situation through the text. The results of the multiple-choice test revealed that the difference between scores of the control group and the explicit group is systematic and it is not due to chance. In addition, focus on form strategy affected the accuracy of L2 learner in EFL context. The results significantly proved the research hypotheses.

Further research in this area includes the study of the impact of explicit instruction on second language learners' performance. Tamayo (2012) analyzed the competence of students in delivering grammatical rules and structures after production in unprompted speech in the secondary school context. Ten Spanish students of English were randomly selected. During the study, an oral interview and a student-specific test were applied as instruments. The results showed that 86 percent of the participants chose the correct grammatical sentences. When considering each explanation, 54 percent of them gave explicit instructions, 29 percent of them gave implicit explanations, and 19 percent did not give any explanation or gave incorrect or unrelated responses. In the stage of judging the grammatical sentences, all of the participants were able to criticize the ungrammatical sentences correctly. Most participants identified correct ungrammatical sentences related to modal verbs followed by 3rd person simple present tense, incorrect pronouns and the lack of the 3rd person simple present morpheme. However, some participants chose the correct ing forms and incorrect conditional structures in the first set while fewer participants chose it correctly in the second set. When focusing on the type of explanations-explicit or implicit, most participants gave an explicit explanation in identifying the ungrammatical sentences with modal verbs, relative pronouns and 3rd person singular morpheme. Conversely, implicit explanation was applied with conditional structures. Lastly, half of the participants explicitly clarified the non-prodrop phenomena and -ing forms.

From the review of literatures and previous studies, it can be seen that explicit instruction can facilitate second language learners to acquire complex grammar structures. Therefore, it was interesting to investigate another form of explicit instruction, i.e., teaching noun clauses explicitly.

\section{Research Questions}

1) Is there a significant difference between the students' knowledge of noun clauses before and after the treatment?

2) To what extent can phrase structure rules help $12^{\text {th }}$-grade 12 students learn noun clauses? 
3) What are the students' opinions toward the explicit instruction by using phrase structure rules on acquisition of noun clauses?

\section{Method}

\section{Participants}

Thirty-six participants were from one class of $12^{\text {th }}$-grade students at a secondary school in Surin. They were studying in $1^{\text {st }}$ semester of academic year 2018 and were almost at the same level of English proficiency.

\section{Research Instruments}

A pretest and posttest consisted of 25 items testing the comprehension of noun clauses were used before and after an experiment. Each item was written under rules of noun phrases that embedded in noun clauses functioning as a subject, an object of a verb and an object of preposition. For each test item, the participants had to underline the noun clauses, translate the underlined noun clause into Thai and translate the whole sentence into Thai. Moreover, a semi-structured interview was used to better understand the participants' learning process in acquiring noun clauses.

\section{Materials}

There were seven lesson plans organized in the explicit instruction framework. Each lesson plan consists of the exercises for the participants to practice. Among the seven lesson plans, three lesson plans were about noun phrases, one lesson plan was on independent and dependent clause and the other three lesson plans were about noun clauses. Other materials included the passages that contained noun phrases and noun clauses in the target position selected from the student's book: Flash on English for grade 12 students.

\section{Data collection}

The study took place in the first semester of academic year 2018. There were 18 sessions in this study. Sixteen sessions were used as an experimental period; two sessions were used for the pretest and post-test. The experiment was conducted within the 50-minute class period for one session. To better understand the participants 'learning process in acquiring noun clauses by using phrase structure rules, the semi-structured interview was conducted.

\section{Data Analysis and criteria of the test difficulties}

To categorize the data, the pretest and posttest were checked by using the following criteria. The total score of the test was 75. It was separately scored into three parts; each part scored 25.

\section{Results}

To answer the research question 1, "Is there a significant difference between the students' knowledge of noun clauses before and after the treatment?", the mean scores of the pretest and posttest were compared. Table 1 showed a comparison of pretest and posttest mean scores. 
Table 1: Comparison of pretest and posttest mean scores

\begin{tabular}{|l|l|l|l|l|l|l|}
\hline & Mean & $\mathbf{N}$ & S.D. & t & df & Sig. (2-tailed) \\
\hline Pretest & 6.14 & 36 & 3.900 & -16.052 & 35 & .000 \\
\hline Posttest & 42.78 & 36 & 15.575 & & & \\
\hline
\end{tabular}

$(\mathrm{p}<.01)$

From Table 1, the mean score of the posttest $(\mathrm{M}=42.78, \mathrm{SD}=15.575)$ has significant differences from the mean score of the pretest $(\mathrm{M}=6.14, \mathrm{SD}=3.900)$ at the .01 level. Therefore, the test result of the experiment revealed that the explicit instruction using phrase structure rules helped improving the knowledge of noun clauses. It can be implied that explicit instruction using phrase structure rules can help the participants perform effectively to acquire noun clauses. Their knowledge of noun clauses after the treatment was significant difference from their knowledge of noun clauses before the treatment.

To answer the research question 2, "To what extent can phrase structure rules help $12^{\text {th }}$-grade students learn noun clauses?", the data were drawn from the mean scores of the three parts of the test: underlining the noun clauses found in each test item, translating the underlined noun clause into Thai and translating the whole sentence into Thai and the test item analysis.

Table 2: Comparison of pretest and posttest mean scores on identifying and translating noun

$$
\text { clauses }
$$

\begin{tabular}{|l|l|l|l|l|l|l|}
\hline & Mean & N & S.D. & T & df & Sig. (2-tailed) \\
\hline Pretest & 1.08 & 36 & 1.500 & -16.725 & 35 & .000 \\
\hline Posttest & 30.78 & 36 & 10.329 & & \\
\hline
\end{tabular}

$(\mathrm{p}<.01)$

From Table 2, the mean score of the posttest $(M=30.78, S D=10.329)$ has significant differences from the mean score of the pretest $(\mathrm{M}=1.08, \mathrm{SD}=1.500)$ at the .01 level. The results revealed that the explicit instruction using phrase structure rules helped improve the knowledge of noun clauses and helped the participants comprehend noun clauses more effectively.

Table 3: Comparison of pretest and posttest mean scores on identifying the noun clauses in the test items

\begin{tabular}{|l|l|l|l|l|l|l|}
\hline & Mean & $\mathbf{N}$ & S.D. & T & df & Sig. (2-tailed) \\
\hline Pretest & .81 & 36 & 1.117 & -22.922 & 35 & .000 \\
\hline Posttest & 19.97 & 36 & 4.748 & & & \\
\hline
\end{tabular}

$(\mathrm{p}<.01)$

From Table 3, when the participants were assigned to underline the noun clauses in the test items, the results showed that the mean score of the posttest $(\mathrm{M}=19.97, \mathrm{SD}=4.748)$ has significant difference from the mean score of the pretest $(\mathrm{M}=.81, \mathrm{SD}=1.117)$ at the .01 level. Therefore, it can be said that after receiving the experiment, the participants have improving the knowledge of noun clauses. In other words, they can distinguish which part of a sentence is a noun clause. 
Table 4: Comparison of pretest and posttest mean scores on translating the underlined noun

$$
\text { clauses }
$$

\section{$(\mathrm{p}<.01)$}

\begin{tabular}{|l|l|l|l|l|l|l|}
\hline & Mean & $\mathbf{N}$ & S.D. & T & df & Sig. (2-tailed) \\
\hline Pretest & .28 & 36 & .659 & -9.711 & 35 & .000 \\
\cline { 1 - 4 } Posttest & 10.81 & 36 & 6.427 & & & \\
\hline
\end{tabular}

From Table 4, to find out how well the participants understand noun clauses by translating, the mean score of the posttest $(\mathrm{M}=10.81, \mathrm{SD}=6.427)$ has significant differences from the mean score of the pretest $(\mathrm{M}=.28, \mathrm{SD}=.659)$ at the .01 level. It can be implied if the participants can distinguish which part of a sentence is a noun clause, they can appropriately translate it and understand the sentence more accurately.

Table 5: Comparison of pretest and posttest mean scores on translating the whole sentence

\begin{tabular}{|l|l|l|l|l|l|l|}
\hline & Mean & N & S.D. & T & df & Sig. (2-tailed) \\
\cline { 1 - 3 } Pretest & 5.06 & 36 & 3.488 & -11.389 & 35 & .000 \\
\hline Posttest & 11.97 & 36 & 5.902 & & & \\
\hline
\end{tabular}

$(\mathrm{p}<.01)$

Table 5 showed that the mean score of the posttest $(\mathrm{M}=11.97, \mathrm{SD}=5.902)$ has significant differences from the mean score of the pretest $(\mathrm{M}=5.06, \mathrm{SD}=3.488)$ at the .01 levels. The finding indicates that when the participants can distinguish the part of a sentence that embedded with a noun clause, they can similarly comprehend the overall meaning of a sentence.

Table 6 showed the percentage of the correct answers in the posttest divided by the function of noun clauses.

Table 6: Correct answers in the posttest divided by the function of noun clauses

\begin{tabular}{|l|l|l|l|}
\hline $\begin{array}{l}\text { Functioning of Noun } \\
\text { Clauses }\end{array}$ & Test items & $\begin{array}{l}\text { Number of the test } \\
\text { items }\end{array}$ & $\begin{array}{l}\text { \% of the correct } \\
\text { answers }\end{array}$ \\
\hline as a subject & $\begin{array}{l}2,3,5,8,10,13,18, \\
22,25\end{array}$ & 9 & 48.46 \\
\hline as an object of a verb & $\begin{array}{l}1,6,7,9,11,12,15, \\
17,23,24\end{array}$ & 10 & 61.02 \\
\hline $\begin{array}{l}\text { as an object of a } \\
\text { preposition }\end{array}$ & \begin{tabular}{l}
$4,14,16,19,20,21$ \\
\hline
\end{tabular} & 6 & 63.27 \\
\hline
\end{tabular}

From the results shown above, the noun clause acting as an object of a preposition has got the highest percentage of the correct answers at $63.27 \%$, the noun clause acting as an object has got $61.02 \%$, and the noun clause acting as a subject has got $48.46 \%$. These can be implied that in overall, the participants can understand the noun clause acting as an object of a preposition better than the other two positions.

To answer the research question 3, "What are the students' opinions toward the explicit instruction by using phrase structure rules on acquisition of noun clauses?", the results were drawn from the 
semi-structured interview data. There were six questions; the answer of each question was described below.

- Opinion on the explicit instruction

The majority of the participants (31 out of 36) illustrated positive points toward the explicit instruction. They mentioned that explicit instruction by using phrase structure rules helped them understand noun clause easier, translated the meaning of a sentence easier, gained more basic knowledge of phrase structure rules and noun clause and knew how to recognize grammar usage. However, one of them said that she cannot follow the lesson and cannot translate the meaning of the words and sentences.

- The effect of phrase structure rules to acquire noun phrases

The first side in answering this question whether phrase structure rules help acquire noun phrases was that 29 out of 36 participants replied that phrase structure rules help acquire noun phrases because the rules guided them to find the appropriate word to build the phrase correctly. Moreover, the rules helped them know which part of speech can build noun phrases, and how they have to build noun phrases. Furthermore, the rules helped them understand the phrase and sentence structure more and lead them to understand the meaning of sentences; also, helped them translate the meaning of the words. However, seven out of 36 participants responded in the opposite side that was the rules helped them a little to understand the phrases due to their basic knowledge of English.

- The difficulty of using phrase structure rules

Thirty-one out of 36 participants mentioned that the rules were not difficult to learn; it seemed difficult at the beginning, but if they paid attention and practiced, they could understand it. Some of them said the rules were easy to recognize and the rules helped them know the position of the words, so they could distinguish the composition of the phrase easier. However, five out of 36 opposed that the rules were difficult for them because there were a lot of rules to learn and memorize, but the rules were not too difficult to understand.

- The difficulty of phrase structure rules

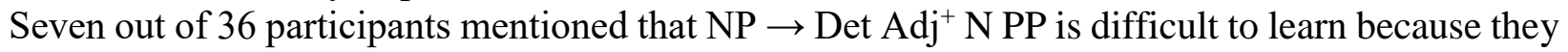
had to find two more adjectives to fill in, put them in the correct order and made them related to the prepositional phrase. Two out of 36 mentioned about $\mathrm{NP} \rightarrow \operatorname{Det} \mathrm{Adj}^{+} \mathrm{N}$ because they knew a few of adjectives.

- The ease of phrase structure

Fourteen out of 36 participants mentioned that noun clauses were easy because when they knew the position and the structure of the noun clauses, they could translate it. Moreover, noun clauses also had key words to notice such as the wh-words used in the sentence.

- The acquisition on noun clauses by using phrase structure rules The majority of the participants (31 out of 36) mentioned that phrase structure rules helped them understand noun clauses because they could define which words, phrases, clauses or a sentence were and which position of words in the sentence was. Moreover, they knew the key word of the clause like relative pronoun, so they could identify the noun clause more correctly. However, five 
participants said that the rules helped them understand noun clause slightly because they were not good at English, so they could not translate some words and sometimes the rules confused them.

\section{Discussion}

\section{Analysis of the effectiveness of explicit instruction by using phrase structure rules on acquisition of noun clauses}

The present research shows that there was a significant difference between the pretest and posttest; therefore, it could be implied that the participants could make use of using phrase structure rules to acquire noun clauses. The study of Andrews (2007) indicated that by using explicit instruction, learners could perform well in comprehending complex structures. In the same fashion with Nezakat-Alhossaini et al. (2014), their study revealed that teaching complex structures by using explicit instruction can be effective. Anderson (2005) suggested that one important factor for successful acquisition of graammatical complex structures is explicit teaching methods. Moreover, the research study conducted by Ling (2015) reveals that the students at the present time have poor knowledge of English grammar. Explicit instruction facilitates students to raise their awareness when learning grammatical structures. This result also supported the theory of Saville-Troike (2006) which introduced that in the working memory there must be a disciplined, controlled stage of presentation of create meaningful learning occurs.

\section{Opinions toward the explicit instruction by using phrase structure rules on acquisition of noun clauses}

- The improvement of the knowledge of noun clauses

The results of the posttest in the identification task showed that the participants have improved the knowledge of noun clauses. On the other hand, they can distinguish which part of a sentence is a noun clause. The study proved that when the participants learned how the complex sentences were constructed through phrase structure rules, they also gained the knowledge of determining the main clause and the subordinate clause in a sentence. As Brinton and Brinton (2010) defined, a phrase structure rule consists of a set of ordered rules, which are applied stepwise. Also, Wijaya (2017) mentioned that phrase structure rules furnish from a small set of rules to an entire sent of sentences. Therefore, phrase structure rules are rules that define a group of words into phrases, and these phrases have their own function that can construct a meaningful sentence.

- The difficulty in translating noun clauses

For translation task that the participants had to translate noun clauses, some of them with low proficiency level had some difficulty in translating. Even though, the meanings of the words were provided, the participants with low proficiency level could not decode the meaning appropriately. In contrast, the participants with higher proficiency level found it easy to comprehend the meaning of the whole sentence because of the provided meanings of the words and the instruction of the rules. This supports Saville-Troike (2006) that when second language learners start learning a second language, they need to contribute their attention to comprehend or produce basic vocabulary and syntactic structures automatically, then they can attend to more complex, higherorder features and content. Comparing to the results between the pretest and the posttest, before the participants receiving the explicit instruction by using phrase structure rules, they could not comprehend noun clauses even though the meanings of the words were provided. This confirmed that learning or knowing either grammar forms or word meanings or vocabulary did not make 
them understand overall image of sentences or context. These components are needed to be connected to each other. In teaching second language learners, form-focused and meaning-focused should be balanced in order to being effective in learning language (Cummins and Davison, 2007). Even though the proficiency of English of some participants were quite low, they also had improvement of acquiring noun clauses. The result in translating the underlined noun clauses showed that they can appropriately translate the clauses. Similarly to the result in translating the whole sentence, phrase structure rules not only help the participants understand noun phrases but also help them accurately comprehend the overall meaning of a sentence. As the results of NezakatAlhossaini, Youhanaee and Moinzadeh (2014)'s study, the explicit instruction had the effect on improvement of students whose proficiency level were intermediate.

- The problem on acquisition of noun clauses in different functions

When considering the functions of noun clauses, the results showed that the participants could perform well on the noun clause functioning as an object of a preposition, the noun clause functioning as an object, and the noun clause functioning as a subject respectively. From these results, noun clauses functioning as a subject was found quite difficult to the participants due to over a half of them could not accurately indicate which words should be a part of a subject (NP), and which should be a predicate (VP). Some of them confused whether the word should be a noun or a verb in the sentence. However, the other two positions were easier because they could be noticed from the relative pronoun and they were in the end of the sentence. If the participants found the relative pronoun, they could identify the noun acting as an object and an object of prepositional phrases. As in Tamayo's study, the result showed that the participants easily recognized relative pronouns due to their specific position in the sentence.

- Factors affecting learning ability

When asking the participants whether using PS rules to acquire noun clauses is difficult, their results were similar. That is, it will not be too hard to learn if they pay attention to the lesson and the teacher's instruction. The results in the present study was similar to Nazari (2012) who mentioned that when the participants concentrated on the content and paid attention to form of the language, they were likely to learn specific grammar structures. Ling (2015) pointed out that explicit instruction facilitated learners to raise their awareness when learning grammatical structures. Therefore, when learning, learners have to have appropriate and effective practice to keep the knowledge later on the working memory.

The explicit instruction was also a way of organizing and reviewing what the participants had already learned. Moreover, Finger (2010) pointed that explicit instruction could help students gain more knowledge in complex context. In addition, the students performed well when they were provided enough linguistic references to nurture their attempts at using the target structure. The research of Tamayo (2012) similarly supported that the explicit instruction helps students have more awareness when using the target structure and also have confident to produce the language. As Celce-Murcia and Larsen-Freeman (1999) indicated, it is interesting that to do phrase structure analysis is essential to be able to improve an understanding of the basic structural units of English. When second language learners have adequate understanding of the structure, they can gain further appropriate knowledge to acquire higher and more complex structure. 


\section{Conclusions and Recommendations}

The study supported that an explicit instruction by using phrase structure rules to help $12^{\text {th }}$-grade students acquire noun clauses is the effective method not only to enhance the students' knowledge of the complex structures but also to raise their awareness in learning English language and vocabulary. The explicit grammar instruction can promote students to learn the structure step by step to make them acquire the structure precisely. If the students understand the basic structural units of the language, they can acquire more complex structure. Furthermore, the students with low proficiency level can improve their grammar knowledge systematically if they have enough practice during the learning process.

By means of explicit instruction, the teachers can prepare the teaching procedures with several frameworks; for example, form-focused instruction or focus on form, form/function mappings or direct instruction. In this study, phrase structure rules were applied as an explicit instruction. Since phrase structure rules consist of a set of ordered rules, they can help learners carefully learn the target rules and apply them in a stepwise technique. Moreover, teaching materials and exercises should be suitable to the students' English proficiency. In this study, even though sentences and passages were selected from the students' book that the students used in the English class, they were considerably difficult for them. Therefore, the teacher should carefully gather sentences and passages with proper vocabulary that is appropriate to the learners' English proficiency. Also, the teacher should adjust materials and exercises to the learners' English proficiency not their Education level.

\section{References}

[1] Anderson, N. (2005). L2 strategy research .In E . Hinkel (ed). Handbook of research in second language teaching and learning .pp. 757-772 .Mahwah, NJ :Lawrence Erlbaum Associates.

[2] Andrews, K. L. (2007). The Effect of Implicit and Explicit Instruction on simple and Complex Grammatical Structures for Adult English Language Learners .The Electronic Journal for English as a Second Language, 11(2). Doi :http//:tesl-ej.org/ej42/a5.html

[3] Archer, A .L., \& Hughes, C. A. (2011). Explicit Instruction: Effective and Efficient Teaching .New York :The Guilford Press.

[4] Brinton, L .J .\& Brinton, D. M. (2010). The Linguistic Structure of Modern English .Amsterdam / Philadelphia: John Benjamins Publishing Company.

[5] Carter, R., McCarthy, M., Mark, G., \& O 'Keeffe .(2016) .English Grammar Today :An A-Z of Spoken and Written Grammar. Cambridge :Cambridge University Press .

[6] Celce-Murcia, M \& Larsen-Freeman, D. (1999). The Grammar Book (2 ${ }^{\text {nd }}$ Eds). USA: International Thomson Publishing.

[7] Ellis, R. (2009). Implicit and Explicit Learning, Knowledge and Instruction .In D .Singleton (ed). Implicit and Explicit Knowledge in Second Language Learning, Testing and Teaching (pp. 3-25). Great Britain: Short Run Press.

[8] Finger, I. (2010). The Role of Explicit Instruction in the Acquisition of the Present Perfect .Revista Brasileira de Linguística Aplicada 10 (4), pp. 837-858 .(doi :10.1590/S1984-63982010000400002

[9] Fotos, S. (2001). Cognitive Approaches to Grammar Instruction .In M .Celce-Murcia (ed), Teaching English as a Second or Foreign Language, pp. 276-283. USA :Thomson Learning.

[10] Gahrouei, V. M. (2012). Effect of Explicit Instruction on Comprehension of English Present Perfect by Persian EFL Learners .Procedia Social and Behavioral Sciences, 70)2013(, )1472-1476 .(doi: 10.1016/j.sbspro.2013.01.213 
[11] Goeke, J. L. (2009). Explicit Instruction: A Framework for Meaningful Direct Teaching .USA : Pearson Education.

[12] Hall, T \&\& Vue, G. (2004). Explicit Instruction. Wakefield, MA :National Center on Accessing the General Curriculum .doi : http//:aem.cast.org/about/publications/2002/ncac-explicitinstruction.html

[13] Ling, Z. (2015). The Role of Explicit Grammar in Language Teaching .Sino-US English Teaching, 12)10(,) 766-770.(doi:10.17265/1539-8072/2015.10.005

[14] Nazari, N. (2012). The Effect of Implicit and Explicit Grammar Instruction on Learners' Achievements in Receptive and Productive Modes. Procedia Social and Behavioral Sciences, 70(2013), (156-162). doi: 10.1016/j.sbspro.2013.01.051

[15] Nezakat-Alhossaini, M, Youhanaee, M, \& Moinzadeh, A. (2014). Impact of Explicit Instruction on EFL Learners' Implicit and Explicit Knowledge: A Case of English Relative Clauses. Journal of Language and Linguistic Studies, 10(2), 183-199.doi: http://dergipark.gov.tr/download/articlefile/104821

[16] Payne, T. E. (2006). Exploring Language Structure: A Student's Guide .New York :Cambridge University Press .

[17] Rahimpour, M .\& Salimi, A. (2010). The Impact of Explicit Instruction on Foreign Language Learners Performance .Procedia Social and Behavioral Sciences, 2, pp. 1740-1746 .doi: 10.1016/j.sbspro.2010.03.976

[18] Scott, C. M. (2009). A Case for the Sentence in Reading Comprehension .Language, Speech, and Hearing Services in Schools, 44, 184-191 .doi :1061-1461/09/4002-0184.

[19] Tamayo, A. G. (2012). The Role and Effect of Explicit Grammar Instruction in SLA. doi : http//:academica-e.unavarra.es/bitstream/handle/2454/15020/73570_Gonzalez $\% 20$ Tamayo, $\% 20$ Andrea.pdf?sequence $=1$.

[20] Wijaya, A. (2017). Phrase Structure Rules. Awin Language. Retrieved on April 30, 2018 from http://awinlanguage.blogspot.com/2012/05/phrase-structure-rules.html.

\footnotetext{
*Corresponding author.

E-mail address: wachiraporn.k@gmail.com
} 